\title{
BIOREMEDIATION OF THE DIESEL-CONTAMINATED SOIL OF THE BRAZILIAN ANTARCTIC STATION
}

\author{
http://dx.doi.org/10.4322/apa.2014.087
}

\section{Juliano C. Cury ${ }^{1, *}$, Hugo E. Jesus², Helena D. M. Villela ${ }^{3}$, Raquel S. Peixoto ${ }^{2}$, Carlos E. G. R. Schaefer ${ }^{4}$,} Marcia C. Bícego ${ }^{5}$, Diogo A. Jurelevicius², Lucy Seldin², Alexandre S. Rosado²

\author{
${ }^{1}$ Universidade Federal de São João del Rei - UFSJ, Campus Sete Lagoas, \\ Rod. MG 424, Km 47, Itapuã, CP 56, CEP 35701-970, Sete Lagoas, MG, Brazil \\ ¿Laboratório de Ecologia Microbiana Molecular, Universidade Federal do Rio de Janeiro - UFRJ \\ Av. Brigadeiro Trompowsky, Ilha do Fundão, CEP 21949-900, Rio de Janeiro, RJ, Brazil \\ ${ }^{3}$ Departamento de Bioquímica, Instituto de Química, Universidade de São Paulo - USP, \\ Av. Professor Lineu Prestes, 748, Bloco 9 Superior, Sala 0970, Butantã, CEP 05508-000, São Paulo, SP, Brazil \\ ${ }^{4}$ Departamento de Solos, Universidade Federal de Viçosa - UFV, Av. Peter Henry Rolfs, s/n, \\ Campus Universitário, CEP 3657-000, Viçosa, MG, Brazil \\ Instituto Oceanográfico, Universidade de São Paulo - USP, Praça do Oceanográfico, \\ Cidade Universitária, CEP 05508-120, São Paulo, SP, Brazil \\ *e-mail: jccury@hotmail.com
}

\begin{abstract}
Antarctic soils are under constant risks of oil contamination due the presence of scientific stations. Bioremediation is the best choice for their recovery. However, before taking the initiative, it is important to test their effect on hydrocarbon depletion and microorganisms. Furthermore, it is important to search for hydrocarbon degraders and bioindicators for monitoring. Our studies showed that the low concentration of $N$ may be causing the recalcitrance of the hydrocarbons in the soil. The microbial characterization revealed alteration of structure and low diversity of the microbial communities in the diesel-polluted soils. The results of an ex situ microcosm experiment revealed depletion of the hydrocarbons content due the aeration and the application of $N$ fertilizer, as well as effects under the microbial communities. An in situ microcosm experiment with the application of $N$ fertilizer and oil-degrader bacterial species previously isolated confirmed the changes under the microbial community. However, it is important to point out that the impact of the fertilizer under microbial community is lower than the oil impact. The present data provides information that allows us to propose the appropriate methodology that can be applied in the area of the Brazilian Antarctic Station for the bioremediation process. In addition, to provide information that allows us to propose an appropriate action plan using better recommended materials (e.g. type and dose of fertilizer; stock of consortia of degraders strains) that will be available for immediate use in the case of new contaminations due to fuel spills in the new Brazilian Antarctic Station.
\end{abstract}

Keywords: Bioremediation, hydrocarbons, Antarctic, soil

\section{Introduction}

Since the installation of scientific stations, Antarctic soils are under constant risk of fuel spills, especially due to the leaking of tanks, diesel transference and vehicle refueling (Aislabie et al., 2004). Anthropogenic activities like these spills can damage the equilibrium of the delicate Antarctic environments, which used to possess the last remaining pristine zones on Earth (Reinhardt \& Van Vleet 1986; Delille et al., 2004).
In some cases, the attempt to cleanup can be made using physical and chemical methods. However, for the Antarctic environments this is not so simple. Displacement of the machinery necessary for the application of physical methods would be very expensive, whereas the application of chemical methods would be dangerous considering the risks of additional environmental impacts. Therefore, bioremediation techniques have been considered an appropriate remediation technology for polar soils, being 
relatively more cost-effective and benign (Aislabie et al., 2006).

Bioremediation techniques are based on the ability of some microorganisms to use the petroleum hydrocarbons as energy source (Alexander, 1994). The monitored natural attenuation is the best cost-effective choice to be applied in oil-polluted sites considering the low-risk and presenting high rates of hydrocarbon degradation. However, in polar soils the environmental conditions are suboptimal for biodegradation (Aislabie et al., 2006). As for some soils out of the Polar Regions, a cause of hydrocarbon recalcitrance can be the depletion of nutrients (especially $\mathrm{N}$ and $\mathrm{P}$ ). An alternative to overcome this problem is the technique of biostimulation (Alexander, 1994), with the addition of fertilizers (e.g. N-P-K, MAP, DAP). However, these additions must be made carefully due the typical coarsetextured, low-moisture Antarctic soils because excess levels of fertilizers can inhibit hydrocarbon biodegradation by decreasing soil water potentials (Aislabie et al., 2006). Other potential limitations for the activity of degraders present in Antarctic soils include low temperature and moisture, alkalinity and the potentially inhibitory effect of toxic hydrocarbons (Aislabie et al., 2006).

Since the microorganisms are responsible for the degradation of the hydrocarbons, it is very important to know their dynamics. According to Aislabie et al. (2006), studies have confirmed the presence of hydrocarbondegrading bacteria in polluted polar soils. Beside, Luz et al. $(2004,2006)$ demonstrated that genes involved in hydrocarbons degradation are present in the region of the Brazilian Antarctic Station (EACF). Additionally, it is known that the presence of oil can change the microbial diversity of Antarctic soils (Saul et al., 2005), and the knowledge of how it occurs may be important for bioindicators selection and further monitoring.

The aim of this work was to characterize the soil properties, the extent of oil contamination and the microbial diversity of polluted and adjacent unpolluted soils of the Brazilian Antarctic Station. Beyond that, we aimed to test the impact of the application of different doses of fertilizer and previously selected degrader strains on depletion of the hydrocarbons and changes in microbial community structure, to propose an efficient and sustainable alternative to minimize the oil pollution at EACF.

\section{Materials and Methods}

The sampling site is located on the front of the Brazilian Antarctic Station. The area close to the fuel tanks was subjected to a 20,000-L diesel spill in 1986. Previous analysis indicates that the reached soil contains variable concentrations of hydrocarbons in its subsurface (0.5-1.0 m) (data not shown). Subsurface staining and smell was evident at several areas near the fuel tanks, indicating the presence of the hydrocarbons. Five superficial $(1 \mathrm{~m})$ soil samples were collected in triplicate in March 2010, during the Antarctic Summer. Three samples (1, 2 and 3) were collected in the oil-polluted area, whereas the other two samples (4 and 5) were collected in the oil-unpolluted area (Figure 1).

The structure and diversity of the microbial communities of the soil samples are characterized using DGGE and SSU rDNA sequencing methods, respectively. To confirm the indigenous bacterial hydrocarbons degrading potential we performed a survey by PCR using specific primers for genes involved in degrading pathways.

We performed ex situ and in situ microcosm bioremediation experiments to test the hydrocarbons depletion and the impact of the treatments under the microbial communities. In the ex situ experimental doses of MAP fertilizers (biostimulation) were tested, whereas in the in situ microcosm a concentration of MAP plus the reintroduction of bacterial degraders previously isolated from the contaminated soil (bioaugmentation) were tested.

\section{Results}

Nitrogen is present in extremely low levels in the soil samples collected in the Brazilian Antarctic Station before the fertilizer application. After two months since the application of the MAP fertilizer, the content of $\mathrm{N}$ became detectable and ranged from 0.02 to 0.08 dag. $\mathrm{kg}^{-1}$ in the soil of the in situ microcosm experiment. Figure 2 shows the content of hydrocarbons of the original soil samples collected in oil-polluted ( 1 to 3 ) and oil-unpolluted (4 and 5) areas and in oil-contaminated and oil-uncontaminated soils after the microcosm experiment. We can observe a linear decrease of hydrocarbons amount from point 1 . After 60 days of incubation, the hydrocarbons content decreased linearly until the treatment with $250 \mathrm{mg} \mathrm{N} \cdot \mathrm{kg}^{-1}$.

The DGGE analyses revealed that the collection points harbor different bacterial community structures since 


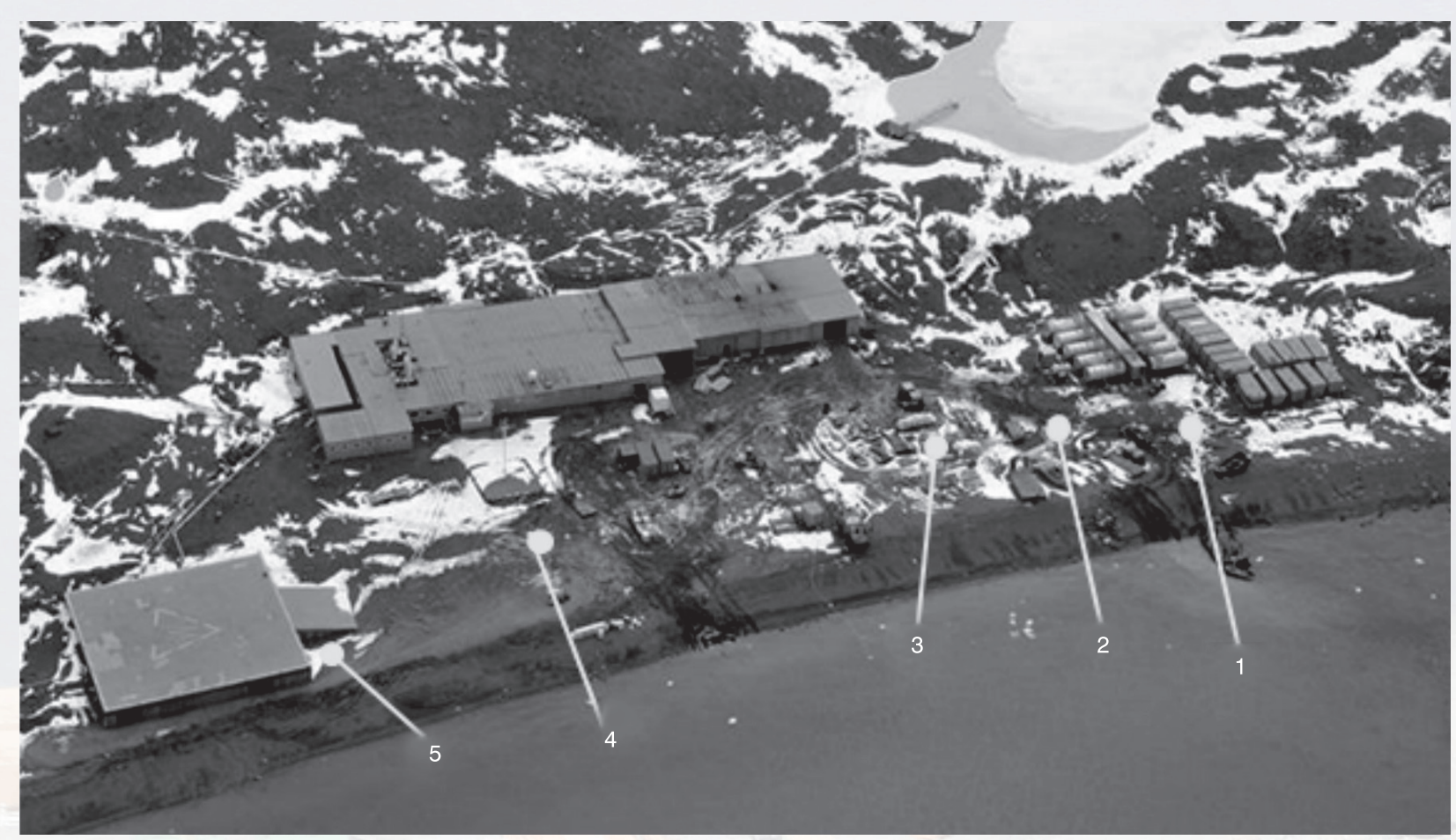

Figure 1. Soil sampling points in the front of the Brazilian Antarctic Station. Samples 1 to 3 were collected in the oil-polluted area whereas the samples 4 and 5 were collected in the oil-unpolluted area.

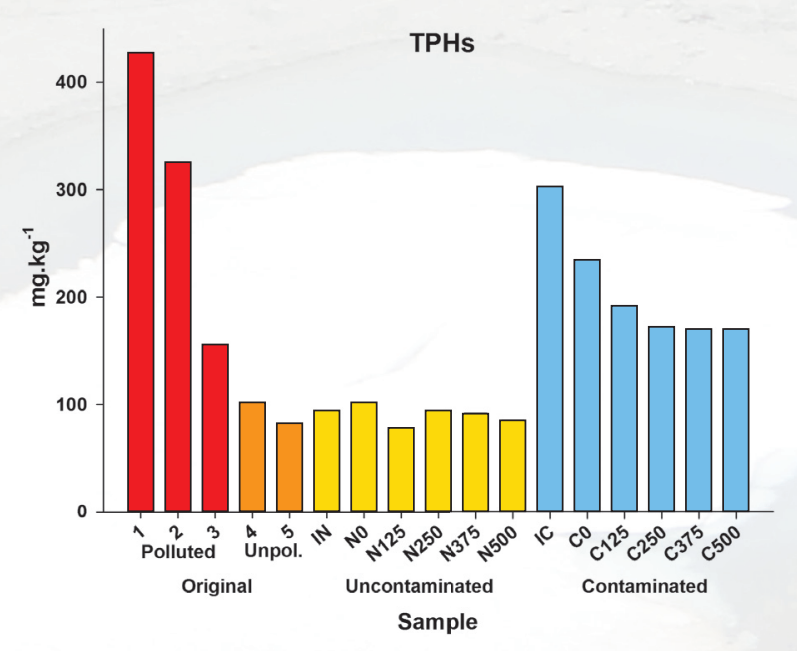

Figure 2. TPHs (total petroleum hydrocarbons) content of soil samples collected in the front of the Brazilian Antarctic Station and after the microcosm experiment. Samples 1 to 3 were collected in the oil-polluted area whereas the samples 4 and 5 were collected in the oil-unpolluted area. I: initial content, calculated as the mean of content of the original soil samples. $\mathrm{N}$ : mixture (1:1) of the oil-unpolluted soil samples (4 and 5). C: mixture (1:1:1) of the oil-polluted soil samples (1,2 and 3). Numbers after the letters indicate the amount of added Nitrogen $\left(\mathrm{mg}^{\mathrm{kg}} \mathrm{kg}^{-1}\right)$ the repetitions of the triplicate or duplicate used always grouped together (Figure 3). The dendrograms shows a strong tendency of grouping due to the presence or absence of the hydrocarbon pollution. Furthermore, the DGGE analysis showed that the application of fertilizer and the reintroduction of bacterial degraders influence the determination of the structure of the bacterial communities of the soil (Figure 4). The SSU rDNA sequence results indicate a tendency of higher bacterial and microeukaryotic diversity in the oil-uncontaminated soil (Figure 5), indicating a toxic effect of the diesel present in the area.

The results from PCR amplification of key genes encoding bacterial hydrocarbon degradation pathways showed that expected fragments of alkB gene, encoding for aerobic alkane degradation, and bamA gene, the biomarker of aromatic degradation by anaerobic bacteria, were found in both contaminated and uncontaminated soils. The Grampositive $\alpha$-subunit-RHD do not presented amplification in the oil-uncontaminated soil samples and the $\alpha$-subunit- 
RHD from Gram-negative was not amplified only for the samples of the oil-uncontaminated soil of the sampling point 4 . Fragments of the expected size of benzyl- and alkylsuccinate synthase genes ( $b s s A$ and $a s s A$ ) were only detected on lower oil-contamination level soil (sampling point 3), and in all oil-uncontaminated soils.

\section{0}

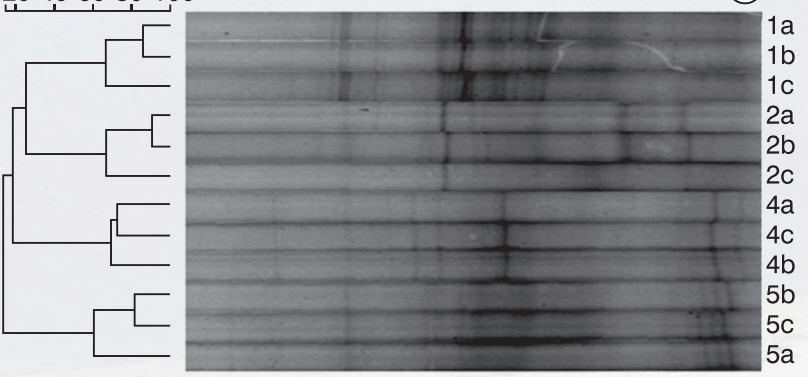

(a)

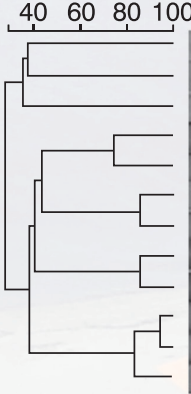

(b)

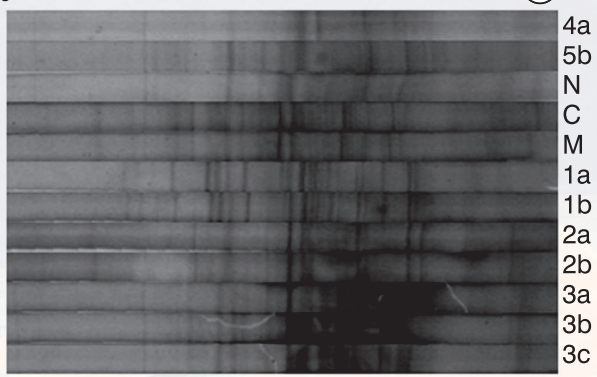

Figure 3. DGGE profiles of PCR-amplified 16S rDNA gene fragments of bacterial communities of the soil samples collected in oil-polluted (1 to 3$)$ and oilunpolluted (4 and 5) areas of the Brazilian Antarctic Station. a) Samples 1, 2, 4 and 5 where the triplicate was used. b) Samples 1 and 2 in duplicate, sample 3 in triplicate and samples 4, 5, N (mixture 1:1 of samples of oil-unpolluted area), C (mixture 1:1:1 of samples of oil-polluted area) and M (mixture 1:1 of C and $\mathrm{N})$. Clustering analysis was based on Pearson's correlation index and the unweighted pair-group method with arithmetic averages.
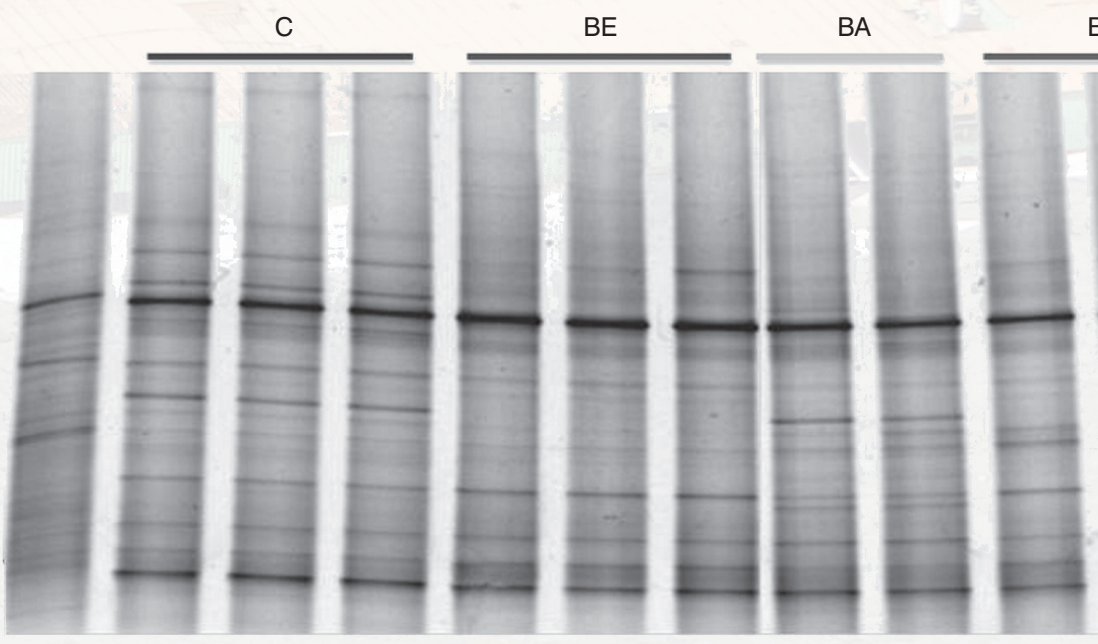

BEBA

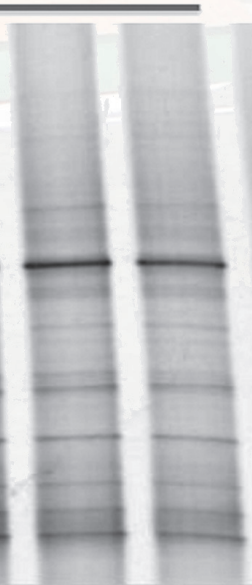

C
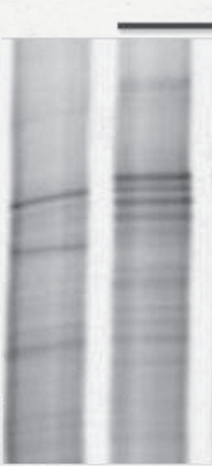

BE

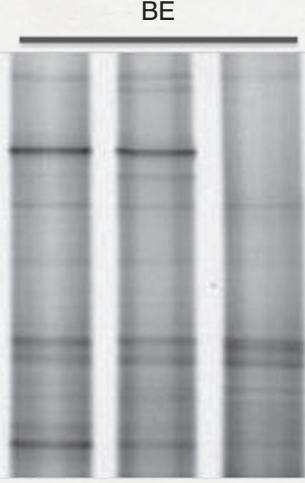

BA

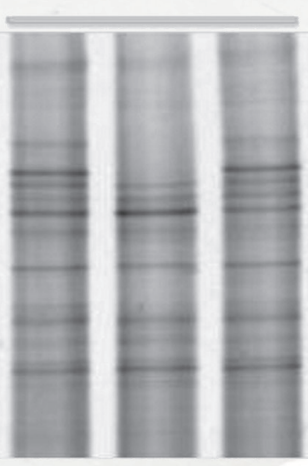

BEBA

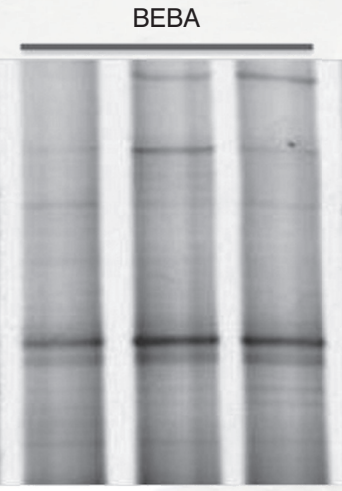

(a)

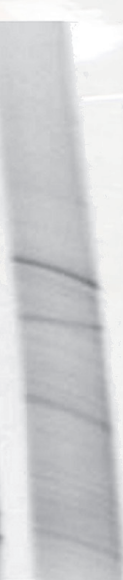

(b)

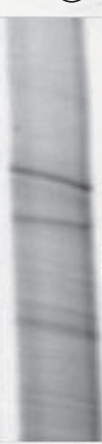

Figure 4. DGGE profiles of PCR-amplified $16 \mathrm{~S}$ rDNA gene fragments of bacterial communities of soil with a history of contamination a) and soil uncontaminated added with $2 \%$ of diesel. C: control; BE: biostimulation (250 mg.kg-1 N); BA: bioaugmentation; BEBA: biostimulation plus bioaugmentation. 

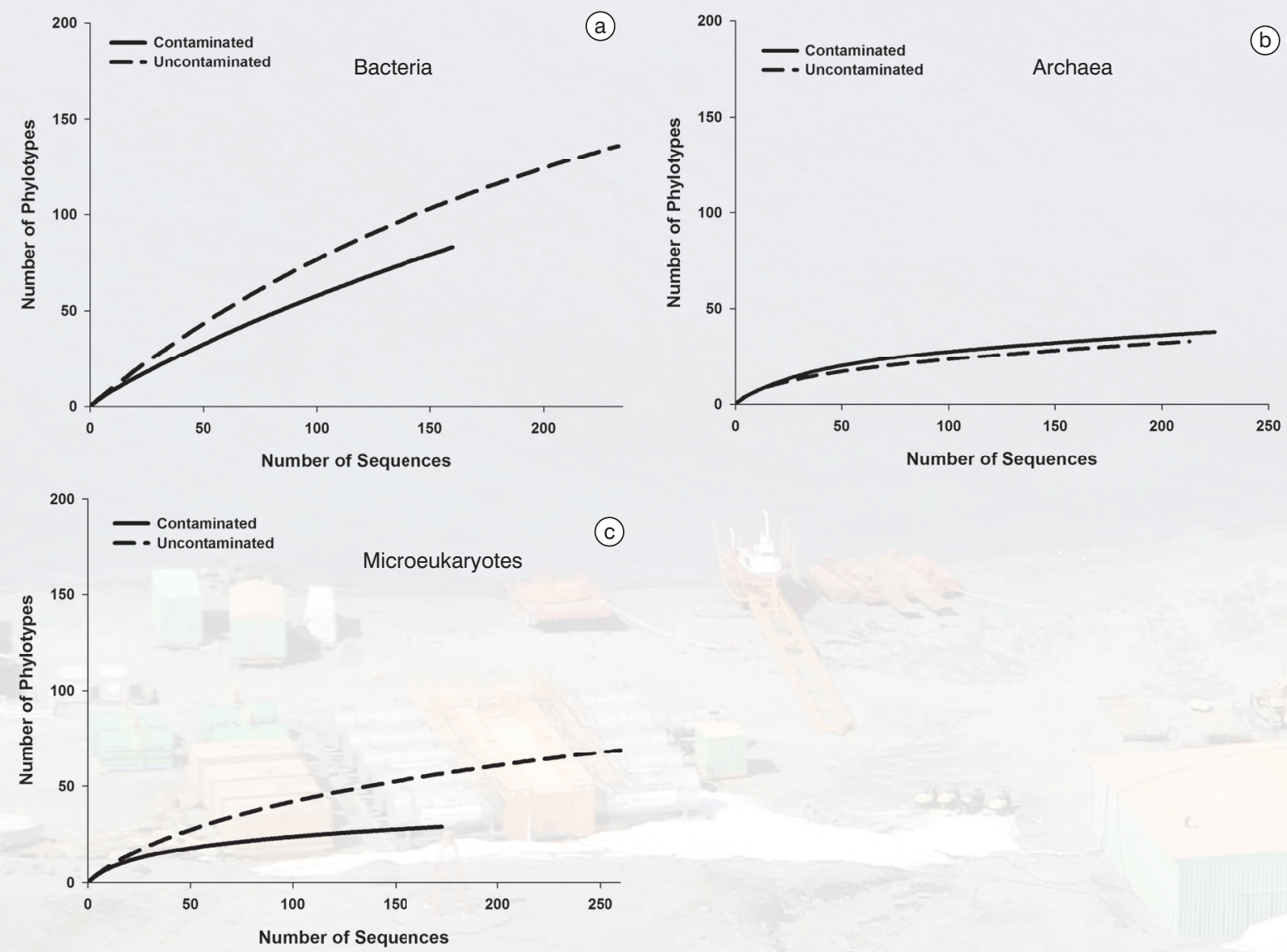

Figure 5. Rarefaction curves calculated using DOTUR ${ }_{0.03}$. The partial sequences of microbial SSU rRNA genes from Antarctic oil-contaminated and oiluncontaminated soils (mixture 1:1:1 and 1:1 of samples of oil-polluted and oil-unpolluted areas of the Brazilian Antarctic Station, respectively) was used. a, b, c) curves of each library of each bacterial, archaeal and microeukaryotic domains respectively.

\section{Discussion and Conclusion}

The recalcitrance of hydrocarbons in cold soils may be due characteristics as: low temperatures (Haider, 1999), lack of final electron acceptors (especially oxygen) (Johnsen et al., 2005), low nutrient concentrations or availability (especially $\mathrm{N}$ and P) (Aislabie et al., 2006), or the absence of microorganisms capable of using hydrocarbons as $\mathrm{C}$ source (Johnsen et al., 2005; Huesemann et al., 2002). Two of the cited factors must be contributing to the hydrocarbon recalcitrance in the soil of the Brazilian Antarctic Station: the nutrient content, especially Nitrogen, considering the negligible amounts of this element in soil; and the lack of oxygen as electron acceptor, considering that the polluted area remains under constant water logging and soil compression due the thaw of the upstream snow and the constant traffic of vehicles, respectively, which decreases the oxygen diffusion. The absence of degrading microorganisms not seems to be one recalcitrance factor considering the positive results obtained in the PCR of the tested genes involved in the hydrocarbon degradation. These results indicate that the microbial community of the oil-polluted soil of the Antarctic Brazilian Station is able to perform metabolic pathways of the hydrocarbon degradation. An indication of the microorganisms participation in the hydrocarbon depletion via degradation is the dose-response effect observed with the application of the Nitrogen. The application of $\mathrm{N}$ at a rate between 125 and $250 \mathrm{mg} \cdot \mathrm{kg}^{-1}$ seems to be sufficient to promote further 
degradation of the hydrocarbons regardless the effect of the aeration.

The present data provides information that allows us to propose the appropriate methodology that can be applied in the area of the Brazilian Antarctic Station for the bioremediation process. In addition, it provides information that allows us to propose an appropriate action plan using better recommended materials (e.g. type and dose of fertilizer; stock of a consortia of degraders strains) that will be available for immediate use in the case of new contaminations due to fuel spills in the Brazilian Antarctic Station.

\section{Acknowledgements}

This work integrates the National Institute of Science and Technology Antarctic Environmental Research (INCTAPA) that receives scientific and financial support from the National Council for Research and Development (CNPq process: $n^{\circ}$ 574018/2008-5) and Carlos Chagas Research Support Foundation of the State of Rio de Janeiro (FAPERJ $n^{\circ}$ E-16/170.023/2008). The authors also acknowledge the support of the Brazilian Ministries of Science, Technology and Innovation (MCTI), of Environment (MMA) and InterMinistry Commission for Sea Resources (CIRM).

\section{References}

Aislabie, J.; Balks, M.R.; Foght, J. \& Waterhouse, E.J. (2004). Hydrocarbon spills on Antarctic soils: effect and management. Environmental Science \& Technology, 38(5): 1265-1274.

Aislabie, J.; Sauld, D.J. \& Foght, J.M. (2006). Bioremediation of hydrocarbon-contaminated polar soils. Extremophiles, 10: 171-179.

Alexander, M. (ed.) (1994). Biodegradation and Bioremediation. San Diego: Academic Press Inc.

Delille, D.; Coulon, F. \& Pelletier, E. (2004). Biostimulation of natural microbial assemblages in oil-amended vegetated and desert sub-Antarctic soils. Microbial Ecology, 47:407-415.

Haider, K. (1999). Microbe-soil-organic contaminant interactions. In: Adriano, D.C.; Bollag, J.M.; Frankenberger, W.T. \& Sims, R.C. (Eds.). Bioremediation of contaminated soils. Madison: ASA/CSSA/SSSA. p. 33-51.

Huesemann, M.H.; Hausmann, T.S. \& Fortman, T.J. (2002). Microbial factors rather than bioavailability limit the rate and extent of PAH biodegradation in aged crude oil contaminated model soils. Bioremediation Journal, 6(4): 321-336.

Johnsen, A.R.; Wick, L.Y. \& Harms, H. (2005). Principles of microbial PAH-degradation in soil. Environmental Pollution, 133(1): 71-84

Luz, A.P.; Pellizari, V.H.; Whyte, L.G. \& Greer, C.W. (2004). A survey of indigenous microbial hydrocarbon degradation genes in soils from Antarctica and Brazil. Canadian Journal of Microbiology, 50: 323-333.

Luz, A.P.; Ciapina, E.M.P.; Gamba, R.C.; Lauretto, M.S.; Farias, E.W.C.; Bicego, M.C.; Taniguchi, S.; Montone, R.C. \& Pellizari, V.H. (2006). Potential for bioremediation of hydrocarbon polluted soils in the Maritme Antarctic. Antarctic Science, 18(3): 335-343.

Reinhardt, S.B. \& Van Vleet, E.S. (1986). Hydrocarbons of Antarctic midwater organisms. Polar Biology, 6:47-51.

Saul, D.J.; Aislabie, J.M.; Brown, C.E.; Harris, L. \& Foght, J.M. (2005). Hydrocarbon contamination changes the bacterial diversity of soil from around Scott Base, Antarctica. FEMS Microbiology Ecology, 53: 141-155. 